\title{
Heparin therapy: A simpler test of control
}

\author{
ANTHONY J. HANDLEY 1 \\ From the Department of Medicine, Westminster Hospital, London
}

SYNOPSIS A bedside test of heparin activity (whole blood activated partial thromboplastin time) was assessed during clinical control of anticoagulation. It correlated closely $(r=0.94)$ with the whole blood clotting time but had a number of advantages.

Experimental evidence has suggested that the optimum dose of heparin is that which maintains a patient's whole blood clotting time over twice the normal time (Carey and Williams, 1960; Gurewich and Thomas, 1965). This level of anticoagulation can be accurately maintained by using an intravenous infusion pump (Handley, 1967), and can be shown to be therapeutically effective, at least as far as prophylaxis against deep vein thrombosis is concerned (Handley, Emerson, and Fleming, 1972). However, the dose of heparin required to produce a given anticoagulant effect in an individual patient varies widely (O'Sullivan, Hirsch, McCarthy, and De Gruchy, 1968), and there is thus a need for some form of haematological control. The standard test used is the whole blood clotting time (WBCT) (Lee and White, 1913). This is time-consuming and very dependent both upon standardization of technique and on cleanliness of clotting tubes. A variety of other coagulation tests have been shown to correlate reasonably well with the WBCT, including the partial thromboplastin time (MacAulay, Frisch, and Klionsky, 1968), activated partial thromboplastin time (Pitney, Pettit, and Armstrong, 1970), and plasma heparin assay (Pitney et al, 1970). None would appear to be better than the WBCT and all require to be performed in the laboratory. Under experimental conditions the whole blood activated partial thromboplastin time ('activated clotting time' or AcCT) is a bedside test which seems to correlate well with the WBCT, and to have certain advantages (Blakely, 1969; Estes, 1970). A slightly modified version of this test was compared with the WBCT during clinical control of heparin therapy.

\section{Subjects and Methods}

The subjects were 20 patients receiving heparin by

${ }^{1}$ Present address: Brompton Hospital, Fulham Road, London, SW3 6HP.

Received for publication 12 December 1973. continuous intravenous infusion for the treatment of $i$ deep vein thrombosis or pulmonary embolism or as prophylaxis against thromboembolism following myocardial infarction. The dose was initially 20000 units 12-hourly, without a 'loading dose', but was adjusted as necessary to produce a WBCT between two and four times normal. The whole blood clotting time and AcCT were measured simultaneously as often as necessary until this degree of anticoagulation was achieved. Some blood samples were deliberately taken within a short time of the start of the heparin in order to obtain pairs of tests at the lower end of the therapeutic range. Alterations in heparin dosage, however, were only made on the results of tests performed at least six hours after the start of $\Omega$ therapy. Similar pairs of tests were also performed on blood from 30 normal control subjects.

\section{Whole Blood Clotting Time}

One $\mathrm{ml}$ of blood was carefully added immediately after venepuncture to each of four glass tubes:$(9 \mathrm{~mm} \times 75 \mathrm{~mm})$ which had been washed in acid 3 . and alcohol and dried in an oven. The tubes were $\delta$ incubated in a water bath at $37^{\circ} \mathrm{C}$ and all four tilted $₹$ gently every 30 seconds until a clot formed. The 윽 mean of the four clotting times was recorded to the nearest 15 seconds.

\section{Activated Clotting Time}

Kaolin suspension, $0.1 \mathrm{ml}$, in Tris buffer $(0.5 \mathrm{mg} / 100 \stackrel{\mathrm{N}}{\mathrm{N}}$ $\mathrm{ml}$ at $\mathrm{pH} \mathrm{7.4)}$ and $0.1 \mathrm{ml}$ of partial thromboplastin $\omega$ (Thrombofax, Ortho) were added to each of two disposable plastic tubes $(8 \mathrm{~mm} \times 65 \mathrm{~mm})$ in a water bath at $37^{\circ} \mathrm{C}$. After leaving time for the $\Phi$ reagents to reach $37^{\circ} \mathrm{C}, 0.5 \mathrm{ml}$ of freshly drawn? blood was added to each tube which was then closed with a plastic stopper. Both tubes were $\frac{O}{\mathbb{D}}$ inverted every 10 seconds until the blood clotted. The mean of the two clotting times was recorded to the nearest five seconds. 


\section{Results}

The WBCT and AcCT were measured in 30 control subjects. The mean times obtained were WBCT $4 \cdot 2$ minutes (range 3-5.5 minutes; SD, 0.48) and AcCT 68.5 seconds (range 50-90 seconds; $\mathrm{SD}, 7 \cdot 0$ ).

The whole blood clotting time and AcCT were measured simultaneously on 38 samples of blood from 20 patients receiving heparin. The results obtained are shown in the figure. The regression line

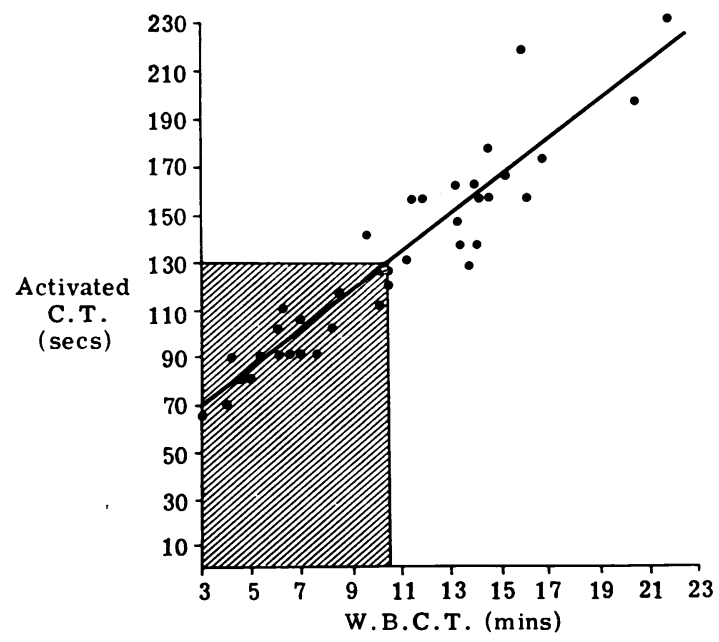

Fig Comparison of whole blood clotting time and 'activated clotting time'. Correlation coefficient $r=0.94$. Results within the shaded portion are considered to be below the minimum therapeutic requirement, but are included to demonstrate the linear correlation at these levels of anticoagulation.

is drawn; the correlation coefficient $r=0.94$. The minimum acceptable degree of anticoagulation was a WBCT of 10.5 minutes. This represents twice the upper limit of normal (mean +2 SD). Sixteen estimations gave results below this level but 12 of these were on samples of blood drawn soon after the start of heparin. The remaining four samples were from patients who had received more than six hours of therapy. In these cases the dose of heparin was increased, further clotting times being measured until the degree of anticoagulation was satisfactory. All pairs of WBCT and AcCT are shown in the figure to demonstrate that the relationship between the two tests remains linear below and throughout the therapeutic range.

Some AcCT tests were performed additionally at room temperature. Very poor reproducibility was obtained between the two tubes and the correlation with WBCT was also very poor. This is similar to the findings of Ray and Harper (1971).

\section{Discussion}

The AcCT has been shown to correlate well with the WBCT in the control of heparin therapy. It will be seen that doubling the AcCT is not the same as doubling the WBCT. Since published recommendations for optimum heparin dosage have been based upon the WBCT it would seem reasonable to use this test as the standard. The corresponding range for AcCT can then be found from the figure. Assuming that one wishes to prolong the WBCT to between two and four times the upper limit of normal, the therapeutic ranges are: WBCT 10.5-20 minutes; AcCT 130-200 seconds.

The AcCT had a number of advantages over the WBCT: (a) the endpoint of clotting was much clearer. (b) The time taken to perform the test was much shorter. (c) Disposable plastic tubes gave similar results and were more convenient to use than glass tubes. $(d)$ The technique was easily taught to medical and nursing staff and reproducible results were obtained more readily than with the WBCT.

There were a number of minor disadvantages which included the need for a water bath (also required for most other coagulation tests), the need to keep the partial thromboplastin in a refrigerator, and the need to pipette accurately quantities of $0 \cdot 1$ $\mathrm{ml}$, particularly when the test was performed by ward staff. This last difficulty was overcome by providing stoppered disposable plastic tubes, each containing the required amounts of reagents and marked with a line to which blood should be added. These were kept in ward refrigerators and transferred to the water bath shortly before use.

I am grateful to the physicians of Westminster Hospital for allowing me to study patients under their care. This work was undertaken whilst in receipt of the H. A. M. Thompson Fellowship from the Royal College of Physicians, London.

\section{References}

Blakely, J. A. (1969). A rapid bedside method for the control of heparin therapy. Amer. Heart J., 78, 838-839.

Carey, L. C., and Williams, R. D. (1960). Comparative effects of dicoumarol, tromexan and heparin on thrombus propagation. Ann. Surg., 152, 919-922.

Estes, J. W. (1970). Kinetics of the anticoagulant effect of heparin. J. Amer. med. Ass., 212, 1492-1495.

Gurewich, V., and Thomas, D. P. (1965). Pathogenesis of venous thrombosis in relation to its prevention by dextran and heparin. J. Lab. clin. Med., 66, 604-612.

Handley, A. J. (1967). Heparin administration by constant infusion pump. Brit. med. J., 2, 48i-184.

Handley, A. J., Emerson, P. A., and Fleming, P. R. (1972). Heparin in the prevention of deep vein thrombosis after myocardial infarction. Brit. med. J., 2, 436-438. 
Lee, R. I., and White, P. D. (1913). A clinical study of the coagulation time of blood. Amer. J. med. Sci., 145, 495-503.

MacAulay, M. A., Frisch, C. R., and Klionsky, B. L. (1968). Relationship of the partial thromboplastin time to the Lee-White coagulation time. Amer. J. clin. Path., 50, 403-407.

O'Sullivan, E. F., Hirsch, J., McCarthy, R. A., and De Gruchy, G. C. (1968). Heparin in the treatment of venous thromboembolic disease: administration, control and results. Med. J. Aust., 2, 153-159.

Pitney, W. R., Pettit, J. E., and Armstrong, L. (1970). Control of heparin therapy. Brit. med. J., 4, 139-141.

Ray, P. K., and Harper, T. A. (1971). Comparison of activated recalcification and partial thromboplastin tests as controls of heparin therapy. J. Lab. clin. Med., 77, 901-907.

\section{Reports and Bulletins prepared by the Association of Clinical Biochemists}

The following reports and bulletins are published by the Association of Clinical Biochemists. They may be obtained from Dr D. H. Orrell, Department of Pathology, Royal Infirmary, Chorley New Road, Bolton BL1 4QS. The i prices include postage, but air mail will be charged extra. Overseas readers should remit by British Postal or Money Order. If this is not possible the equivalent of 50p is the minimum amount that can be accepted.

SCIENTIFIC REPORTS

3 Automatic Dispensing Pipettes: an assessment of 35 commercial instruments September 1967 P. M. G. BROUGHTON, A. H. GOWENLOCK, G. M. WIDDOWSON, and K. A. AHLQUIST $80 \mathrm{p}(\$ 2)$

4 An Evaluation of five Commercial Flame Photometers suitable for the Simultaneous Determination of Sodium and Potassium March 1970 P. M. G. BROUGHTON and J. B. DAWSON 80 p (\$2)

\section{SCIENTIFIC REVIEWS}

1 The Assessment of Thyroid Function March 1971 F. V. FLYNN and J. R. HOBBS $60 \mathrm{p}(\$ 1.50)$

2 Renal Function Tests Suitable for Clinical Practice January 1972 F. L. MTTCHELL, N. VEALL, and R. W. E. WATTS $60 \mathrm{p}(\$ 1.50)$

TECHNICAL BULLETINS

9 Determination of Urea by AutoAnalyzer November 1966 RUTH M. HASLAM 40p (\$1)

11 Determination of Serum Albumin by AutoAnalyzer using Bromocresol Green October 1967 B. E. NORTHAM and G. M. WIDDOwson 40p (\$1)

13 An Assessment of the Technicon Type II Sampler Unit March 1968 B. C. GRAY and G. K. MCGOWAN 40p (\$1)

14 Atomic Absorption Spectroscopy: an outline of its principles and a guide to the selection of instruments May 1968 J. B. DAWSON and P. M. G. BROUGHTON 40p (\$1)

15 A Guide to Automatic Pipettes (2nd edition) June 1968 P. M. G. BROUGHTON 40p (\$1)

16 A Guide to Automation in Clinical Chemistry May 1969 P. M. G. BROUGHTON 60p (\$1.50)

17 Flame Photometers: a comparative list of 17 instruments readily available in Britain August 1969 P. WILDING 60p $(\$ 1.50)$
19 Spectrophotometers. A comparative list of low-priced $O$ instruments readily available in Britain May 1970 윽 C. E. WILDE and P. SEWELL 60p (\$1.50)

20 Quantities and Units in Clinical Biochemistry June 1970 P. M. G. BROUGHTON 60p (\$1.50) More than 30 copies in units of 10 at $20 \mathrm{p}$ each

21 Filter Fluorimeters: A comparative list of 18 instruments September $1970 \mathrm{H}$. BRAUNSBERG and s. S. BROWN $60 \mathrm{p}(\$ 1.50)$

22 Bilirubin Standards and the Determination of Bilirubin by Manual and Technicon AutoAnalyzer Methods January 1971 BARBARA BILLING, RUTH HASLAM, and N. WALD 60p (\$1.50)

23 Interchangeable Cells for Spectrophotometers and Fluorimeters September 1971 S. S. BROWN and A. H. GOWENLOCK $60 \mathrm{p}(\$ 1.50)$

24 Simple Tests to Detect Poisons March 1972 B. w. MEADE et al. $60 \mathrm{p}(\$ 1.50)$

25 Blood Gas Analysers May 1972 K. DIXoN 60p $(\$ 1.50)$

26 Kits for Enzyme Activity Determination September 1972 S. B. ROSALKI and D. TARLOW 80p (\$2.00)

27 Assessment of Pumps Suitable for Incorporation into Existing Continuous Flow Analytical Systems November 1972 A. FLECK et al. 60p (\$1.50)

28 Routine Clinical Measurements of Transferrin in 6 Human Serum September 1973 K. DIXON 60p (\$1.50)

29 Control Materials for Clinical Biochemistry (5th T edition) September 1973 J. F. STEVENS 60p (\$1.50)

30 Notes on the Quality of Performance of Serum $\stackrel{\odot}{\Phi}$ Cholesterol Assays September 1973 s. S. BROWN 60p (\$1.50) 